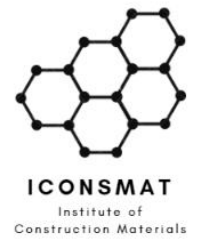

Content list available at ICONSMAT

Journal of Construction Materials

Journal homepage: www.iconsmat.com.au/publication
Article history:

Received 5 September 2020

Received in revised form

7 September 2020

Accepted 8 September 2020

Available online

2 October 2020

\title{
Reinforced concrete problems and solutions: A literature review
}

\author{
Omar Alhamad ${ }^{* 1}$, Waleed Eid ${ }^{2}$ \\ ${ }^{1}$ LimaK Company; Kuwait \\ ${ }^{2}$ Kuwait University, Kuwait \\ *Corresponding Author: Omar Alhamad; E: omrkh24@gmail.com
}

\begin{abstract}
Reinforced concrete is a concrete lined with steel so that the materials work together in the resistance forces. Reinforcement rods or mesh are used for tensile, shear, and sometimes intense pressure in a concrete structure. Reinforced concrete is subject to many natural problems or industrial errors. The result of these problems is that it reduces the efficiency of the reinforced concrete or its usefulness. Some of these problems are cracks, earthquakes, high temperatures or fires, as well as corrosion of reinforced iron inside reinforced concrete. There are also factors of ancient buildings or monuments that require some techniques to preserve them. This research presents some general information about reinforced concrete, the pros and cons of reinforced concrete, and then presents a series of literary studies of some of the late published researches on the subject of reinforced concrete and how to preserve it, propose solutions or treatments for the treatment of reinforced concrete problems, raise efficiency and quality for a longer period. These studies have provided advanced and modern methods and techniques in the field of reinforced concrete.
\end{abstract}

DOI: 10.36756/JCM.v2.1.1 (C2020 Institute of Construction Materials

\section{Keywords}

Reinforced concrete; Treatment; Concrete; Corrosion; Seismic; Cracks 


\section{Introduction}

Concrete is one of the most used building materials in the world. Concrete is a mixture of powdered cement, sand, aggregate such as stone, and water. It allows for treatment and has high compressive strength and low tensile strength. In contrast, reinforced concrete (RC) is a mixture of concrete with reinforcements (steel bar), see Fig. 1. Other types of reinforcements such as carbon nano platelets [1, 2] also has recently been introduced which are beyond the scope of this article.

$\mathrm{RC}$ is a building material discovered in late $19_{\text {th }}$ century and was credited for inventing it into Joseph Louis Lampot in 1848 and has obtained a patent through the design of 1867 reinforced garden basins, and then beams-patented concrete beams and elements for railways and road fences. After that, the major developments of the armed concrete began since the year 1900 [3]. RC columns (RCC) are usually structural linear elements, which are generally casted vertically. RC is containing embedded plates, steel bars, or fibers that support the material. Also, RC is responsible for carrying loads from floors to foundations. The stability, inflexibility, and strength of any structure are closely associated with the strength and robustness of the columns. The capacity to carry loads is maximized by these materials, and because of this, RCC is widely used in all construction. In fact, building materials have become the most used. Therefore, the concrete columns must be reinforced identically to the global analysis of the structural system, in order to ensure quality, efficiency and security.

RC, as a building material, is used extensively around the world because of its importance in the development of urbanization. It has a lot of pros and cons. For example, some advantages of armed concrete are:

1. Compared to other construction materials, $\mathrm{RC}$ has high compressive strength.

2. RC can withstand a great deal of tensile stress due to the reinforcement provided.

3. Fire resistance and weather.

4. Considered to be more robust building system than any other building system for RC.

5. Initially, RC, as liquid materials, can be formed in an almost unlimited range of shapes.

6. Less skilled labour to establish the structure, compared to using steel in the structure.

On the other hand, some disadvantages:

1. Tensile strength up to ten compressive strength.

2. RC steps are mixing, casting, and processing, which undoubtedly have a significant impact on the final power.

3. The cost of models used for casting RC is quite higher.

4. Deflation causes crack expansion and loss of strength [4].

There are many topics to be presented such as: concrete materials and different environments that are exposed to concrete and durability, concrete durability in the global building code, distressed RC tradition structures, concrete cracks, corrosion, and causes of deterioration, and solutions for the treatment of these problems, for example concrete injectors, repair by concrete, repair and prevention of rust, especially cathodic protection, reinforcing bars made of fiber reinforced plastic (FRP).

Developed countries spend a huge proportion of their annual infrastructure budgets on repairs, maintenance and replacement of present and new structures, which is a significant indication of deficiencies in past construction practices, designs and techniques. Gardner et al. [5] have done a survey of the problems encountered in the recent concrete construction. Market research results are 
presented according to the questions asked, as gathered in the original market survey report. The market research has shown that the main problems faced by concrete (old and new construction) are in the projects that the participants have worked on over the last five years is as shown in Fig. 2.

This research will be focused on four major problems facing RC. Section II will be a literature review and will present these four problems, namely corrosion, cracks, seismic, and thermal. In this Section, we will explain these problems and contributions made by researchers in their treatment, how they were analyzed, and solutions are provided, while Section III will be about the conclusion of this paper.
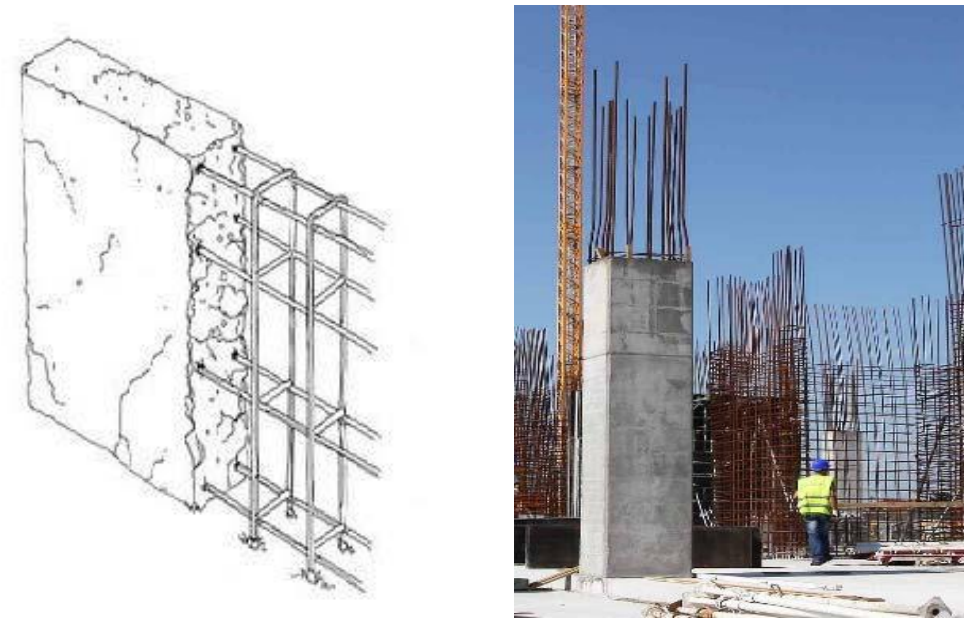

Figure 1 Reinforced Concrete

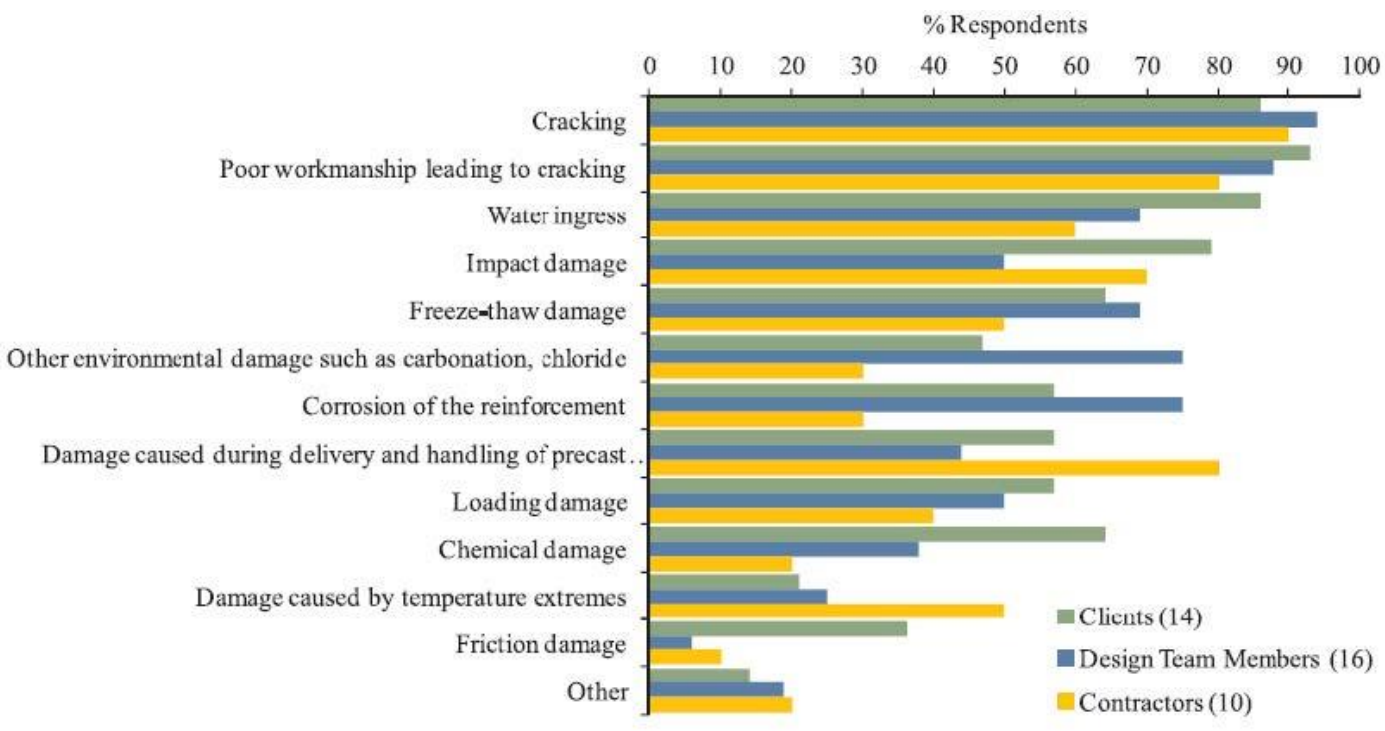

Other includes: Expansion due to ASR. Salt damage. Sulphate damage. Fire damage. Concrete specs have been higher than required which has caused cracking due to brittleness.

Figure 2 The main reasons of damage in concrete structures [5]. 


\section{Literature Review}

There are many problems for using RC, and many researchers have identified problems and solutions to these problems. In this Section, we provide a literature review of these four problems that RC faces.

\section{A. Corrosion}

Corrosion of embedded reinforcement in concrete is one of the essential reasons for the deterioration of many existing RC structures [6]. It also causes significant costs to be treated and replaced or repaired. For example, in the United States, the cost of treating and replacing concrete RC highways has been eroded for nearly 15 years by more than $\$ 6.3$ billion [7].

Thomas [8] discussed the relationship of cement hydration and corrosion of steel, where there is a mechanical similarity between the two processes. The delay of both techniques depends on the presence of thick, non-permeable membranes or layers that protect the interactive surfaces underneath. However, it has been observed that several additives that quicken cement moisturization also reinforce steel corrosion, and those that delay water are usually corrosion inhibitors. Author considered the accelerators of cement moisturizing for use in RC.

Blunt et al. [9] presented a paper that examined whether the resistance to cracks of hybrid fiber (HyFRC) decreases the corrosion rate of steel reinforcement bars in concrete after cyclic loading. After extracting the reinforcing bars to test their surface for corrosion and comparing the estimates of the loss of the microcell and macrocell versus the direct gravity measurements, they observed a delay in starting corrosion and reduced active corrosion rates in the HyFRC beam samples when compared with enhanced samples containing normal concrete matrices in the same load Flexibility.

A study is presented by Fang et. al [10] to study the deterioration of the bond between reinforcing steel and concrete surrounding corrosion. Drag tests were performed to assess the effects of corrosion on bond behaviour and slip. Samples were tested with varying degrees of corrosion under withdrawal and periodic loading, respectively, where 40 have been tested under pull loads. The study is based on the withdrawal test to assess the association properties. The samples were shown after 28 days of treatment in 5\% sodium chloride solution for corrosion of steel bars to different levels of corrosion designed under direct electric current. Samples were then tested to check the strength of the bonding and sliding down the loading drag. It has been observed that the onset of corrosion and its spread in samples depends on several factors, including permeability of concrete matrix, thickness of cover, applied electrical current, density of solution used and environmental temperature. The reinforcing steel used in the test was smooth and deformed, as shown in Fig. 3.

The results were as follows: corrosion levels were reduced for deformed bars without confinement, but corrosion did not have a significant impact on the bond strength of deformed bars with confinement.
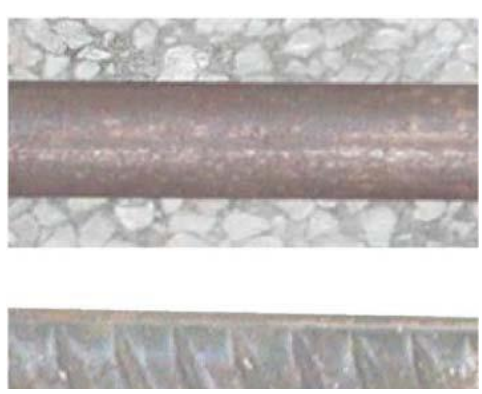

Figure 3 Bars used as reinforcement [16]
As for the smooth bars without confinement, there was a change in the effect of corrosion on the strength of the bond at a certain level, while the strength of the bond increased with the level of corrosion of the smooth bars with confinement. In all published studies on cement cementation, there was general agreement that it should be considered a cause of generalized corrosion in reinforcements, but quantitative data were presented in very few cases. In the present work, the intensity of the attack was adjusted by rapid carbonation of the mortar samples without additives, with $2 \%$ calcium chloride and $3 \% \mathrm{NaNO}_{2}$. It has been shown that a critical 
level of atmospheric moisture must also be present in a large attack that occurs. The polarization resistance (Rp) measurement was used to assess the strength of the reinforcement corrosion. This method has been effectively applied by authors to investigate the corrosion of steel bars in solid concrete samples.

\section{B. Cracks}

Steel fiber RC (SFRC) (see Fig. 4) is a compound material, merging a cement matrix and an intermittent reinforcement, composed of randomly distributed steel fibers in the matrix. It is increasingly used to build civilian infrastructure. Meson et. al [11] presented a review of the published researches on corrosion caused by carbonate and chloride from SFRC. Tackling cracked SFRC exposed to carbonation and chlorides, they proposed a deterioration theory based on damage in the fibre-matrix interface. Regarding the durability of uncracked for SFRC under chloride and carbonate, authors found through the review a comprehensive agreement between regulators and academics. There is a great vision among academics regarding the existence of a critical crack width, less than $0.20 \mathrm{~mm}$, where fiber corrosion is limited and SFRC structural integrity can be guaranteed for long-term exposures.

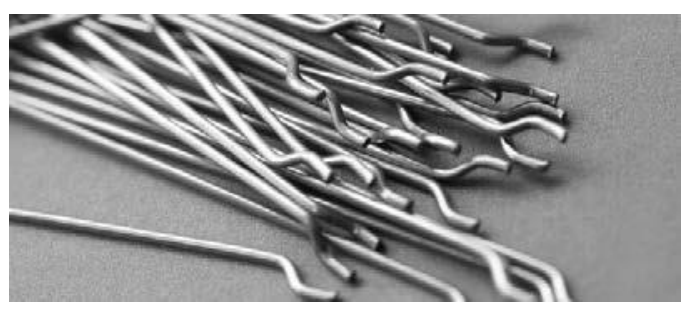

Figure 4 SFRC

RC members are heavily used in civilian infrastructure such as buildings, tunnels, bridges, and dams. Cracks are considered the main cause of damage in RC members. Many researchers have conducted studies and research to develop an effective structural control method for detecting cracks, predicting actions and retrofit procedures. Ahmad et. al [12] applied an experimental cracked RC member, where they have strengthened the fractured members of the armed forces through technical experiments. The proposed experiments from the application of locally applied polymer modified mortar (PMM) consist of cracked beams to increase load capacity using the same material and the same ratio of the mixture and the water cement than the construction of a total of six complete RC packages. The experiment repairs the beams with fractures exceeding $1 \mathrm{~mm}$, using locally modified polymer mortar, and then after 3 days of water the beams were tested again and loaded until failure. The result showed an improvement in load carrying capacity in retrofitting beams and clarity in the effectiveness of the proposed technique in repairing RC members to strengthen existing structure, a significant increase $36 \%$ in load capacity. Also, the study had showed that when more PMM is needed for injection cracks can be obtained more effective results.

The researchers [13] conducted a study to monitor the structural health of RC packages through a composite approach based on smart aggregate (SA) transducers. Where they installed two SA sensors and one operator to measure and test the four-point bending of three RC packs, as shown in Fig. 5 . Power spectral density (PSD) and root-mean-square deviation (RMSD) evaluation as an indicator of damage can be detected and tracked cracking RC packets under gradually increasing loading. The study also showed the possibility of predicting large cracking through a successful precautionary point. 
Xuemei et. al [14] addressed the plastic hinge zone in RC, where it is very important for flexural members since it governs the load and distortion capabilities of the member. The fulfillment of the plastic hinge area is critical to emotional organs because it governs the ability to carry and deform the organ. Authors tackled the analytically with Finite Element (FE) using commercial software programming DIANA. It has been designed and tested using current experimental data including response to load deflection, rotational amplitude and stress distributions of reinforcement. Two-dimensional model and monotonic loading are examined in

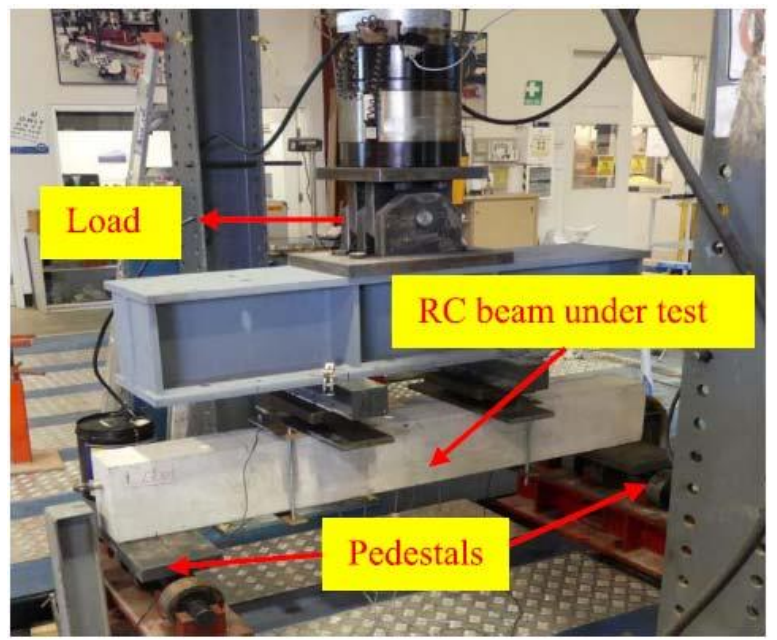

Figure 5 Four-point bending test frame this work, and the Arc-length method is used for numerical solution. The results displayed that advanced FE model presented is capable of simulating complexity of this problem.

\section{Seismic}

Seismic is known as earthquakes. This phenomenon causes damage to modern, old or heritage buildings. Ismail [15] studied the seismic behavior of a typical building based in Cairo, and an investigating was applied using a rapid propulsion tool analysis before and after updating its columns using carbon fiber reinforced polymer (CFRP), see Fig. 6, RC jackets or steel element vests. The specific building contains most typical building defects typical of buildings constructed prior to modern earthquake-resistant design codes. The results showed a great enhanced in ductility, the strength of bending slightly increased due to the contribution of CFRP jackets with tensile strength of reinforcement. also, modified retrofitting techniques have significantly increased the members strength.

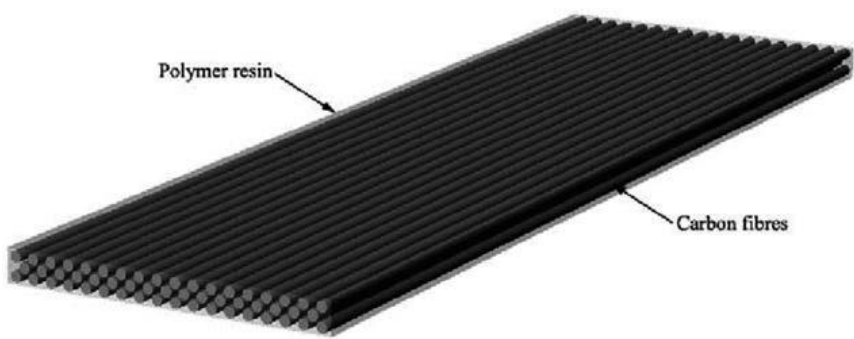

Figure 6 CFRP

Ozkan et al. [16] presented an article to assess the effect of fiber reinforced polymer (FRP) of the cyclic and monotonic behaviour of RCC with soft reinforcements. The primary objective of this study is to investigate the efficiency of CFRP encapsulation on improving the seismic accomplishment of square RCC with low concrete strength and smooth extensions with continuous longitudinal reinforcement and insufficient transverse reinforcement. they applied an experimental, and observed that, while a small side loading capacity (10\% 15\%) was observed, the number of CFRP sheets used to limit the areas of plastic hinges from columns improved significantly from the seismic behaviour of missing columns. Also, Zeinoddinia and Dabiria [17] presented study to evaluate the seismic performance of these structures. The study applied on old building in Egypt, where some of these buildings must be examined against seismic demands. Authors applied smooth rebars. The seismic assessment of the updated structures showed that the seismic 
modification of the reinforced RC structure was smooth because the viscose dampers, which lacked enough flexibility, were more effective than other schemes.

Di Sarno and Manfredi [18] performed a numerical calculation of the seismic performance of the RC frame structure designed for gravitational loads only. Where the study was renovated using BRBs placed along the surrounding boundary. The results of nonlinear analyzes showed that more than $60 \%$ of the total energy was Faded away by the braces, in the event of collapse. Rubaratuka [17] presented a study on the old heritage buildings in Dar es Salaam, what problems they face, and the risks that may occur if they are ignored. Finally, he made general proposals for the preservation of ancient heritage abbeys, for example; provide regulatory personnel with qualified technical personnel, develop and adopt national construction standards, and apply build appropriate technology and strengthen supervision of construction work.

\section{Thermal}

Thermal influences heavily on RC, and may be caused by fires, external factors, or due to high atmospheric temperatures. Bian et al. [18] presented a study on the effect of thermal damage on the physical and mechanical properties of high-performance fiber RC (UHPFRC). Concrete samples were heated in the oven at a rate of $1 \mathrm{C}$ (per min), until the maximum temperature was reached, as illustrated in Fig. 7. This low heating rate confirms that the cracking will only consequence from increasing the temperature and not because of the thermal gradients inside the sample. Four UHPFRC mixtures have been prepared and reinforced with different types of fiber, namely organic fibers (PP or PVA), or Mineral fiber (steel or wollastonite). To induce heat damage to the UHPFRC, samples were subjected to temperatures ranging from 150 to $400^{\circ} \mathrm{C}$. The results exposed that the melting of organic fibers at about $180^{\circ} \mathrm{C}$ builds up a channel through the cement paste. It also critically increases gas permeability. At $400{ }^{\circ} \mathrm{C}$, a $30 \%$ reduction in pressure strength and a Young modulus of about $60 \%$ was observed.

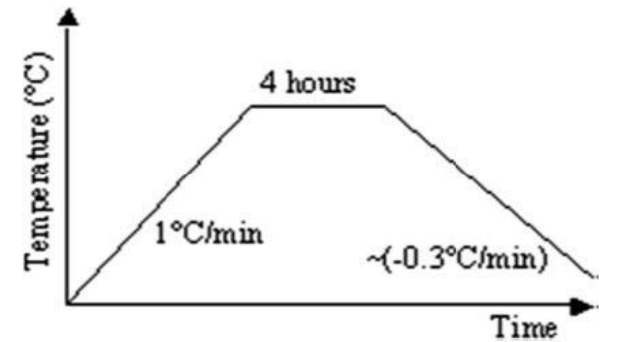

Figure 7 Thermal degradation of concrete models [18]
Ewa and Drzymala [21] conducted a study on the impact of polypropylene fibers (PP) on the thermal behaviour of concrete at high temperatures through thermal analysis. Two types of polypropylene fibers have been applied which differ in shape and size as fillers. Emphasis was placed on the thermal behaviour of PP-RC exposed to heat treatment, i.e. at $200^{\circ} \mathrm{C}$ and $300^{\circ} \mathrm{C}$. The results presented that the presence of polypropylene fibers influenced the thermal firmness of concrete samples. Ozawa and Morimoto [22] considered a study on the effects of three types of fibers; PP

fibers, jute, and water-soluble polyvinyl alcohol (WSPVA) at high temperature in high-performance concrete (HPC). The water vapor pressure in the HPC samples reinforced with the three types of fiber was compared to the saturated water vapor pressure in the samples. The concrete samples of Jute, WSPVA and PP were reported to have not exploded. The maximum water vapor pressure was in the samples of Jute, WSPVA, PP 2.5, 1.5 and 1.0 MPa, respectively. Barrera et. Al [23] provided 44 test trials on RCC subjected to fixed axle loading and lateral side strength. The goal is to gain higher information of the types of elements that will also be useful in calibrating numerical models and validating basic 
methods. Test and analysis concluded very conformist in case of the strength and deformation of the columns.

\section{Conclusion}

In this research, we have provided a brief description of the RC, and what are its pros and cons. We have also presented some of the problems facing RC, whether these problems are natural, or because of human errors as a manufacturer or during implementation. We then presented a collection of some published research on RC and how to address these problems. Since there are many problems facing the RC, we focused through this research on the four most important problems: corrosion, cracks, seismic, and thermal. The researchers reviewed the causes of these problems and the proposed solutions in treating them or reducing their deterioration. We hope in the future to provide studies on other problems or contribute to the treatment of one of these problems.

\section{References}

[1] F. Sartipi, A. Ghari Zadeh, and M. Gamil, "Electrical resistance of graphene reinforced cement paste," Journal of Construction Materials, 2019.

[2] M. Gamil, A. Ghari Zadeh, and F. Sartipi, "A review on graphene reinforced cement composite: technical approach for ecofriendly construction," Journal of Construction Materials, 2019.

[3] http://www.planete-tp.com/en/the-invention-of-reinforced-concrete-andthen-a180.html.

[4] https://civiltoday.com/civil-engineering-materials/concrete/23-advantages-anddisadvantages-of-reinforced-concrete

[5] D. Gardner, R. Lark, T. Jefferson, R. Davies, "A survey on problems encountered in current concrete construction and the potential benefits of self-healing cementitious materials", Case Studies in Construction Materials, Vol. 8, pp: 238-247, 2018.

[6] L. Bertolini, "Steel Corrosion and Service Life of Reinforced Concrete Structures." Structure and Infrastructure Engineering, Vol. 4(2), pp. 123-137, 2008

[7] M. Yunovich, N. G. Yunovich, T. Balvanyos, L. Lave, "Corrosion Cost and Preventive Strategies in the United States - Appendix D: Highway Bridges." Federal Highway Administration, FHWARD-01-157, 2001.

[8] N. L. Thomas," Corrosion problems in reinforced concrete: why accelerators of cement hydration usually promote corrosion of steel" Journal of Materials Science, Vol. 22(9), pp 3328-3334, 1987.

[9] J. Blunt, G. Jen, C.P. Ostertag, "Enhancing corrosion resistance of reinforced concrete structures with hybrid fiber reinforced concrete", Corrosion Science, Vol. 92, pp:182-191, 2015. 
[10] C. Fang, K. Lundgren, L. Chen, Ch. Zhu, "Corrosion influence on bond in reinforced concrete", Cement and Concrete Research, Vol. 34, pp:2159-2167, 2004.

[11] V. Marcos-Meson, A. Michel, A. Solgaard, G. Fischer, C. Edvardsen, T.L. Skovhus, "Corrosion resistance of steel fibre reinforced concrete - A literature review", Cement and Concrete Research, Vol. 103, pp:1-20, 2018.

[12] S. Ahmad, A. Elahi, S.A. Barbhuiya, Y. Farid. "Use of polymer modified mortar in controlling cracks in reinforced concrete beams", Construction and Building Materials, Vol. 27, pp: 9196, 2012.

[13] S. Taghavipour, S. Kharkovsky, W-H. Kang, B. Samali, O. Mirza, "Detection and monitoring of flexural cracks in reinforced concrete beams using mounted smart aggregate transducers", Smart Materials and Structures, Vol. 26, (7pp), 2017.

[14] X. Zhao, Y. Wu, A. Y. Leung, H. F. Lam, "Plastic Hinge Length in Reinforced Concrete Flexural Members", Procedia Engineering, Vol.14, pp:1266 -1274, 2011.

[15] A. Ismail, "Nonlinear static analysis of a retrofitted reinforced concrete building”, Housing and Building National Research Center, Vol. 10, pp: 100-107, 2014.

[16] O. Ozcan, B. Binici, G. Ozcebe, "Improving Seismic Performance of Deficient Reinforced Concrete Columns Using Carbon Fiber-Reinforced Polymers", Engineering Structures, Vol. 30, pp: 1632-1646, 2008.

[17] M. Zeinoddinia, A. Dabiria, "Seismic Analytical Model for Retrofitted Old Reinforced Concrete Structures", Procedia Engineering, Vol. 54, pp: 188 -206, 2013.

[18] L. Di Sarno, G. Manfredi, "Seismic strengthening with buckling restrained braces: application to an existing non-ductile RC framed building", Soil Dynam. Earthq. Eng, 30 (11), pp:1279-1297, 2010.

[19] I. A. Rubaratuka, "Challenges of the Quality of Reinforced Concrete Buildings In Dar es Salaam", International Journal of Engineering Research \& Technology, Vol. 2 (12), pp: 820-827, 2013.

[20] H. Bian, K. Hannawi, M. Takarli, L. Molez, W. Prince, "Effects of thermal damage on physical properties and cracking behavior of ultrahigh-performance", Journal of Materials Science, Vol. 51, pp:10066-10076, 2016.

[21] E. Rudnik, T. Drzymała, "Thermal behavior of polypropylene fiber reinforced concrete at elevated temperatures", Journal of Thermal Analysis and Calorimetry, Vol. 131, pp:10051015, 2018.

[22] M. Ozawa, H. Morimoto, "Effects of various fibres on high-temperature spalling in highperformance concrete". Constr Build Mater. Vol. 71, pp:83-92, 2014.

[23] A.C. Barrera. J. L. Bonet, M. L. Romero, P.F. Miguel, "Experimental tests of slender reinforced concrete columns under combined axial load and lateral force", Engineering Structures, Vol. 33 (12), pp: 3676-3689, 2011. 